\title{
Relationships between force-time curve variables and jump height during countermovement jumps in young elite volleyball players
}

\author{
Javad Sarvestan ${ }^{1, *}$, Mahdi Cheraghi ${ }^{2}$, Masoud Sebyani ${ }^{1}$, Elham Shirzad ${ }^{1}$, and Zdeněk Svoboda ${ }^{3}$ \\ ${ }^{I}$ Faculty of Physical Education and Sport Sciences, Tehran University, Tehran, Iran; ${ }^{2}$ Sport Biomechanics Center, National \\ Olympic and Paralympic Academy of Iran, Tehran, Iran; and ${ }^{3}$ Faculty of Physical Culture, Palacký University Olomouc, \\ Olomouc, Czech Republic
}

Copyright: (C) 2018 J. Sarvestan et al. This is an open access article licensed under the Creative Commons Attribution License (http://creativecommons.org/licenses/by/4.0/).

\begin{abstract}
Background: The importance of vertical jumps has been extensively recognised in sports. Furthermore, the main indicator of success in vertical jumps is the attained height, however, there is lack of knowledge on how the eccentric and concentric force-time curve variables affect the jump height. Objective: The objective of this study was to assess the relationships between eccentric and concentric variables of the force-time curve and jump height in youth volleyball players. Methods: Twelve elite volleyball players (male, Iranian national youth volleyball players, $17 \pm 0.7$ years) have participated in this study. The correlations between the force-time variables, including the peak force, relative peak force, peak power, average power, relative peak power, peak velocity, and modified reactive strength index, of the eccentric and concentric phases and jump height have been assessed based on Pearson's correlation coefficient. Results: Results showed that the average power $(r=.70, p=.034)$, relative peak power $(r=.75, p=.029)$ and peak velocity $(r=.98, p=.004)$ of the concentric phase and modified reactive strength index $(r=.83, p=.014)$ significantly correlated with the jump height. Conclusions: Relative peak power and average power of the concentric phase are shown to affect jump height in young volleyball players, whereby the vertical jump is their integral part.
\end{abstract}

Keywords: stretch-shortening cycle, CMJ, eccentric, concentric

\section{Introduction}

Vertical jump is an integral part of preparation exercises in most modern sports, and require high velocity and power. Many research studies have focused on athletes' vertical jumps, and especially on the attained height (Runge, Rittweger, Russo, Schiessl, \& Felsenberg, 2004; Russo et al., 2003; Salles, Baltzopoulos, \& Rittweger, 2011). Vertical jump is also used for assessing the explosive power of lower extremities, forecasting, and monitoring athletes. Force and power are known as relative factors of sport performance (Carlock et al., 2004; Slinde, Suber, Surer, Edwén, \& Svantesson, 2008).

Most of the previously published research studies assessed lower extremity power by countermovement jumps (CMJ) (Kollias, Hatzitaki, Papaiakovou, \& Giatsis, 2001). CMJ, both free-handed and akimbo-style,

\footnotetext{
* Address for correspondence: Javad Sarvestan, Department of Health and Sports Medicine, Faculty of Physical Education and Sport Sciences, University of Tehran, 15th St., North Karegar St., 1417614418 Tehran, Iran. E-mail: javadsarvestan@ut.ac.ir
}

are types of vertical jumps, and constitute the most useable tests for the assessment of the neuromuscular coordination of athletes (Claudino et al., 2017). In addition, $\mathrm{CMJ}$ is used for the assessment of the fitness level of injured athletes after rehabilitation periods, and for detecting their fitness to return to play (Clanton, Matheny, Jarvis, \& Jeronimus, 2012; Henderson, Barnes, \& Portas, 2010; Olsson et al., 2013). Forcetime (F-T) curve variables of CMJ are utilised to assess neuromuscular and biomechanical features related to lower extremity dynamics (Claudino et al., 2017; Kollias et al., 2001). Additionally, vertical jump tests are performed in accordance to various aims, such as the assessment of the developed force and power in elite athletes who participate regularly in competitions (Cormie, McGuigan, \& Newton, 2010). McGinnis et al. (2016) have used $\mathrm{CMJ}$ to assess the effect of fatigue on performance. Olsson et al. (2013) showed that CMJ and other types of jumps could be used for the assessment and evaluation of athletes' performances, after Achilles tendon tears. Previous research studies have shown that $\mathrm{CMJ}$ has an appropriate validity for assessing explosive 
power of knee extensors. The research that has been conducted by Markovic, Dizdar, Jukic, and Cardinale (2004) showed that CMJ is the most prestigious tool for the power assessment of the lower extremity.

$\mathrm{CMJ}$ includes rapid eccentric muscle contraction followed by concentric muscle contraction, known as the stretch-shortening cycle (SSC). In Schmidtbleicher (1992), CMJ was placed in a slow SSC in instances when the contact time was greater than $0.25 \mathrm{~s}$. SSC is known as a rapid concentric contraction after a rapid eccentric contraction, which increases the stored energy and muscle activity (Cormie et al., 2010). In turn, factors affecting SSC, increase the jump height $(\mathrm{JH})$ by increasing the vertical velocity of the centre of mass. This velocity increases owing to the power of the lower extremity during the concentric phase. Sufficient time needed to produce and transfer force to skeletal systems is one of the most effective mechanisms in SSC. The eccentric phase of SSC provides this opportunity to agonist muscles to generate a substantial force, concurrently providing adequate time to the structures to reach considerable stiffness (JiménezReyes \& González-Badillo, 2011).

Achieving relative peak power (RPP) in different sports where the vertical jump is an integral part, such as volleyball and basketball, can affect the height achieved. Riggs and Sheppard (2009) stated that RPP and average power (AP) have significant correlation with the CMJ height. Given that power is normalised to body weight, it could be pointed out that individual RPP has considerable effects on performance and in reaching the JH. Exclusive review of F-T curve variables in CMJ can help us identify effective factors in JH. Peak power (PP), peak velocity (PV), relative force, average force, and peak force (PF), are reviewed as effective variables in concentric and eccentric phases in most research studies (Cormie et al., 2010; Laffaye, Wagner, \& Tombleson, 2014; Riggs \& Sheppard, 2009).

The vertical jump is vital part of the preparation exercises in most sports, such as volleyball and basketball, where the measures of increased $\mathrm{JH}$, and the capability for increased power output are presented as key factors of success in most of them (Duthie, Young, \& Aitken, 2002; Wisløff, Castagna, Helgerud, Jones, \& Hoff, 2004). Because both of these factors can attain functional and dynamic forms in CMJ, identification of the variables affecting the ultimate height and generated power is important. Reviewing the F-T curve variables in different phases of $\mathrm{CMJ}$ constitutes a good index for an exclusive and comprehensive review of vertical jump performance among youth elite volleyball players, which has not been investigated before. Based on the background discussed above, the objective of this research was to assess the relationship between the F-T variables derived from both the eccentric and concentric phases and JH in young volleyball players.

\section{Methods}

\section{Participants}

Twelve young male elite volleyball players participated in this study, including three setters, three middle blockers, three wing spikers, and three opposite spikers. They had the following anthropometrical features and training experience: age $17 \pm 0.7$ years, body height $189.0 \pm 8.3 \mathrm{~cm}$, body weight $83 \pm 6.1 \mathrm{~kg}$, experience $5.8 \pm 1.9$ years. All of the players who participated in this study were playing in the Iranian pro-league and junior national team. Data were obtained when the players were in the national camp during the pre-Asian competition season, and undertook three plyometric exercise sessions per week. Participants were acquainted with the study's purpose and the methods were explained in detail. Written informed consent was obtained prior to testing, and the study was pre-approved by the Ethical Committee of the Faculty of Physical Education and Sport Sciences, University of Tehran.

\section{Instruments and procedure}

Following a dynamic warm-up for $15 \mathrm{~min}$, subjects performed three CMJs (interspersed by 3 min intervals of rest to prevent fatigue) to a self-selected depth (McMahon, Murphy, Rej, \& Comfort, 2017; McMahon, Rej, $\&$ Comfort, 2017). Subjects were instructed to perform the CMJs as fast and as high as possible, whilst keeping their arms on their hips. Participants stood still during the initial first second of the data collection period (McMahon, Rej, et al., 2017) to allow the determination of their body weight post-testing. All CMJs were recorded at a rate of $1000 \mathrm{~Hz}$ via a Kistler type 9281C force platform using the Bioware 5.11 software (Kistler Group, Winterthur, Switzerland). The raw vertical F-T data for the best CMJ trial were exported and analysed using Microsoft Excel (Version 2013; Microsoft, Redmond, WA, USA).

\section{Data analyses}

The instantaneous centre of mass (COM) velocity was calculated by dividing the vertical force (with the body weight excluded) by the body mass, and then integrating the product using the trapezoidal rule. Instantaneous power was calculated by multiplying the vertical force and velocity data at each time point, and COM displacement was determined by the double integration of the vertical force data (McMahon, Rej, et al., 2017; Owen, Watkins, Kilduff, Bevan, \& Bennett, 2014). Eccentric and concentric PF, PP, and PV, were defined as the 
maximum values attained during the respective concentric phases of the jump. Impulse was calculated during both the eccentric and concentric phases of the jump as the area under the net F-T curve (with the body weight excluded) using the trapezoidal rule (Kirby, McBride, Haines, \& Dayne, 2011). All kinetic data were divided by the body mass to allow for a normalised comparison of these data between athletes. JH was derived from the vertical velocity at take-off (Moir, 2008). A modified reactive strength index (MRSI) was calculated as the $\mathrm{JH}(\mathrm{m})$ divided by the movement time (s) (Ebben \& Petushek, 2010).

Similar to other studies, the CMJ was divided into three phases, namely, unweighting, eccentric, and concentric (Carlock et al., 2004; Ebben, Flanagan, \& Jensen, 2007), to describe the specific impacts of each F-T variables (Figures 1 and 2) at each of its phases on JH. These phases were defined as follows (Figure 1):

- unweighting phase: started when the velocity measure started to decrease from zero and finished when it reached its lowest value (A to B),

- eccentric phase: started immediately after the unweighting phase and lasted until the velocity of the centre of mass became equal to zero (B to $\mathrm{C}$ ),

- concentric phase: started when the velocity of the centre of mass became positive, and lasted until the participant left the force platform ( $\mathrm{C}$ to take off).

\section{Statistical analyses}

The statistical analyses were performed using IBM SPSS Statistics (Version 22 for Windows; IBM, Armonk, NY, USA). Kolmogorov-Smirnov test showed normal data distribution. For determining the relationship between F-T curve variables and MRSI with JH, Pearson's product moment correlations were used. The significance level was $\alpha=.05$.

\section{Results}

Descriptive measures of F-T variables in eccentric and concentric phases are shown in Table 1. Table 2 demonstrates the correlation between the F-T curve variables of the eccentric and concentric phases with the $\mathrm{JH}$ achieved. As it can be observed, although none of the eccentric variables have significant correlation with $\mathrm{JH}$, which may be attributed to the small research sample size, the total eccentric time could be considered as an important factor contributing to JH. In terms of the concentric phase, AP $(r=.70, p=.034)$, RPP $(r=.75$, $p=.029)$, and $\mathrm{PV}(r=.98, p=.004)$ shown a significant correlation with $\mathrm{JH}$. In addition, MRSI is presented to have significant correlation $(r=.83, p=.018)$ with $\mathrm{JH}$.

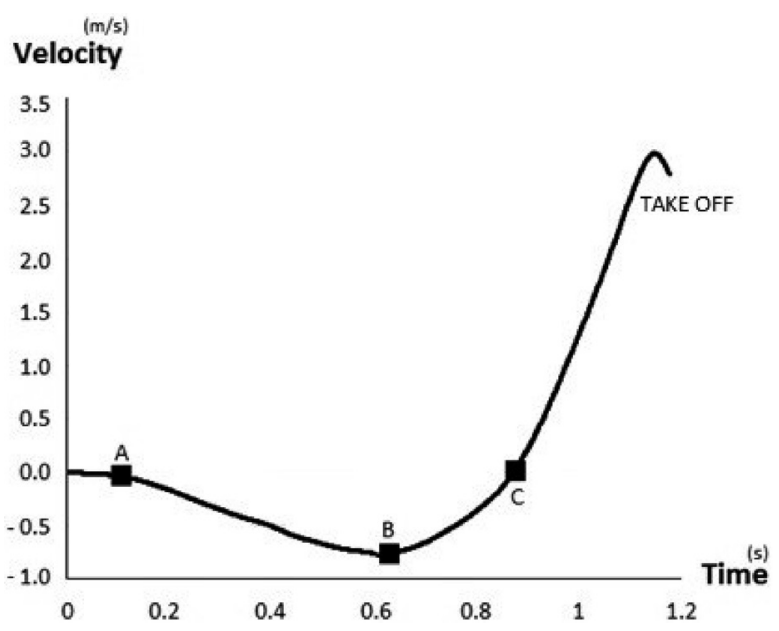

Figure 1. CMJ phases according to the velocity-time curve: (A) onset of the unweighting phase, (B) onset of the eccentric phase, and $(\mathrm{C})$ onset of the concentric phase.

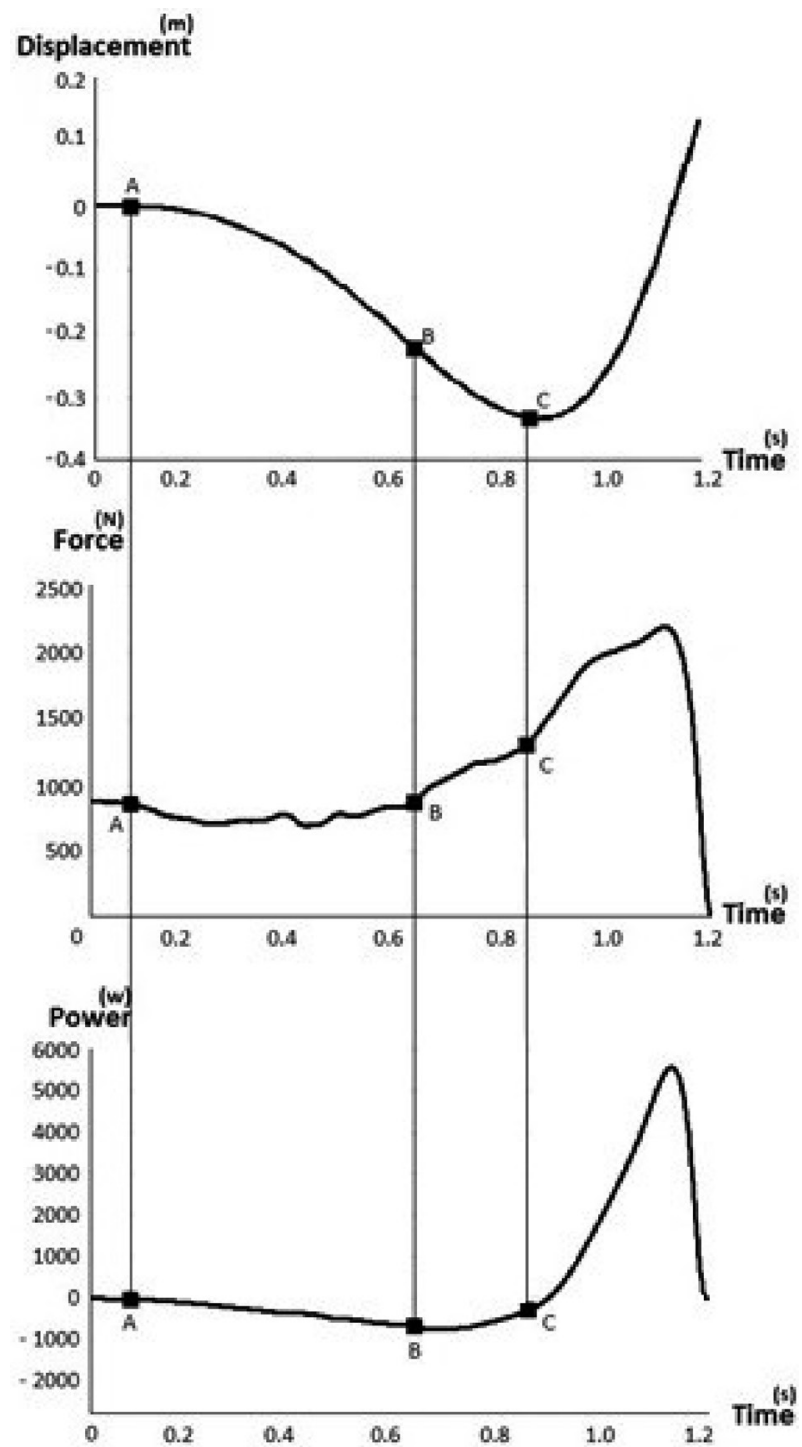

Figure 2. Identification of CMJ phases in displacement-time, F-T, and power-time curves. 
Table 1

Descriptive measures of F-T curve variables in the eccentric and concentric phases

\begin{tabular}{lcc}
\hline & \multicolumn{2}{c}{ Phase } \\
\cline { 2 - 3 } & Eccentric & Concentric \\
\hline Time (ms) & $183 \pm 43$ & $338 \pm 33$ \\
$\quad$ Total time & $74 \pm 2$ & $255 \pm 41$ \\
Time-to-peak power & $965 \pm 57$ \\
$\quad$ Jump total time & $1.25 \pm 0.25$ & $2.98 \pm 0.19$ \\
Peak velocity(m/s) & & \\
Force (N) & $857 \pm 312$ & $1,874 \pm 246$ \\
$\quad$ Peak force & $8.3 \pm 0.25$ & $20.4 \pm 2.23$ \\
Relative peak force & \multicolumn{2}{c}{} \\
Power (W) & $1,323 \pm 390$ & $4,696 \pm 814$ \\
$\quad$ Peak power & $12.03 \pm 0.3$ & $52.75 \pm 0.7$ \\
Relative peak power & $708 \pm 227$ & $2,356 \pm 401$ \\
Average power & $1.0 \pm 0.3$ & $2.5 \pm 0.6$ \\
Impulse (N·m) & \multicolumn{2}{c}{$0.364 \pm 0.06$} \\
Modified reactive strength & \multicolumn{2}{c}{$0.37 \pm 0.05$} \\
$\quad$ index &
\end{tabular}

Table 2

Correlation between jump height and F-T curve variables in the eccentric and concentric phases of CMJ

\begin{tabular}{lcc}
\hline & \multicolumn{2}{c}{ Phase } \\
\cline { 2 - 3 } & Eccentric & Concentric \\
\hline Time (ms) & -.49 & -.57 \\
$\quad$ Total time & .10 & -.38 \\
Time-to-peak power & .35 & \\
Jump total time & -.25 & $.98^{* *}$ \\
Peak velocity (m/s) & & \\
Force (N) & .34 & .32 \\
$\quad$ Peak force & .34 & .28 \\
$\quad$ Relative peak force & & .58 \\
Power (W) & -.27 & $.75^{*}$ \\
$\quad$ Peak power & -.30 & $.70^{*}$ \\
$\quad$ Relative peak power & -.22 & .02 \\
$\quad$ Average power & .31 & \\
Impulse $(\mathrm{N} \cdot \mathrm{m})$ & & $.83^{* *}$ \\
Modified reactive strength & & \\
$\quad$ index & &
\end{tabular}

${ }^{*} p \leq .05,{ }^{* *} p \leq .01$.

\section{Discussion}

The principal objective of this study was to assess the relationship between the eccentric and concentric variables of the F-T curve and $\mathrm{JH}$ in young volleyball players. The main results of this research indicated that no eccentric variable presented a significant correlation with $\mathrm{JH}$. In terms of the concentric phase, PV, AP, and RPP, have been shown to present significant correlations with JH. In addition, MRSI presented a strong significant correlation with $\mathrm{JH}$ in regard to the $\mathrm{CMJ}$ performances of young elite volleyball players.

Achieving the maximum $\mathrm{JH}$ is one of the most important components of sport performances in volleyball players, basketball players, and height jumpers. Vertical jump is detected as an important effective factor in such sports (McMahon, Rej, et al., 2017; Runge et al., 2004; Russo et al., 2003). JH measures, power, and force, whether relative or absolute, are spiffing factors for presenting athlete performance. In a study conducted by Riggs and Sheppard (2009) on elite beach volleyball players, RPP presented a strong correlation with $\mathrm{JH}(r=.90)$, similarly as in our study. The review of the relative measures of variables can elicit more precise criteria on athlete capabilities owing to the nature of each sport. This is because in some sports, like volleyball, basketball, and handball, the ability to jump and perform rapid movements, are factors affecting performance, and represent manifestations of the ability of the athletes to overcome body weight, or relative measures of force or power (Riggs \& Sheppard, 2009). As it can be observed, concentric RPP presents a significant correlation with $\mathrm{JH}(r=.75)$. This could indicate that the power generated by each athlete can specifically affect his $\mathrm{JH}$.

Additionally, Riggs and Sheppard (2009) mentioned that the average power of the concentric phase in CMJ presented a significant correlation with $\mathrm{JH}$ $(r=.67)$. Results presented in this study showed also significant correlation between the AP of the concentric phase and $\mathrm{JH}(r=.70)$.

According to the research conducted by Laffaye et al. (2014) the best way to reach maximum height in jumps is to increase the concentric force and the rate of change of the eccentric force. In addition, the same researchers investigated the correlation between the ratio of the eccentric phase time and the total time as a function of the height, and results showed the existence of a negative correlation. Our results showed that the total time of the eccentric phase presented a negative correlation with $\mathrm{JH}(r=-.49)$ that showed the importance of short eccentric phase duration, however this finding is not significant. It is important to note that reduction of the eccentric phase time leads to an 
increased recruitment of muscle fibres, and according to the velocity-time curves, an increase in contraction velocity of the muscle results in the generation of increased force, which can ultimately increase JH. Of course, it should be noted that a briefer eccentric phase can increase neurostimulation, owing to the muscle spindles and Golgi tendon organ activity.

As it can be observed, none of the eccentric variables has significant correlation with the JH. In Jidovtseff, Quievre, Harris, and Cronin (2014) and the listed classification of effective variables in jumps, the maximum force of the eccentric phase has an impact on eccentric loading, which helps avoid lower limb deformation in landing, and severe landing impacts. This explanation can be a good reason for the statement that the eccentric phase is largely focused on lower-limb injury prevention rather than on the production of force to increase JH. On the other hand, eccentric phase is important for energy storing, and its duration can influence amount of energy utilizable during concentric phase. Although in our study correlation between eccentric phase duration and $\mathrm{JH}$ was not significant $(r=.49)$.

Jidovtseff et al. (2014) indicated, kinetic and kinematic outputs are considerably affected by the jump's style. All of the subjects were young players and this attribute can explain the fact that the differences of the jump performances of participants were influenced by the differences in their training experiences.

One of the study limitations was the small sample size, which according to statistics, is one of the most important factors in statistical power. For this reason, the small sample size in this study must be taken into consideration.

\section{Conclusions}

Our findings confirmed the importance of average and relative peak power of the concentric phase to attain higher jumps. Because these two variables have undeniable effects on the $\mathrm{JH}$ attained, coaches and athletes can focus on these to enhance the athletes' jumping performances. Significant effect of eccentric phase has not been found.

\section{Conflict of interest}

There were no conflicts of interest.

\section{References}

Carlock, J. M., Smith, S. L., Hartman, M. J., Morris, R. T., Ciroslan, D. A., Pierce, K. C., \& Stone, M. H. (2004). The relationship between vertical jump power estimates and weightlifting ability: A field-test approach. Journal of Strength and Conditioning Research, 18, 534-539.

Clanton, T. O., Matheny, L. M., Jarvis, H. C., \& Jeronimus, A. B. (2012). Return to play in athletes following ankle injuries. Sports Health, 4, 471-474.

Claudino, J. G., Cronin, J., Mezêncio, B., McMaster, D. T., McGuigan, M., Tricoli, V., \& Serrão, J. C. (2017). The countermovement jump to monitor neuromuscular status: A meta-analysis. Journal of Science and Medicine in Sport, 20, 397-402.

Cormie, P., McGuigan, M. R., \& Newton, R. U. (2010). Changes in the eccentric phase contribute to improved stretch-shorten cycle performance after training. Medicine \& Science in Sports \& Exercise, 42, 1731-1744.

Duthie, G. M., Young, W. B., \& Aitken, D. A. (2002). The acute effects of heavy loads on jump squat performance: An evaluation of the complex and contrast methods of power development. Journal of Strength and Conditioning Research, 16, 530-538.

Ebben, W., Flanagan, E., \& Jensen, R. (2007). Gender similarities in rate of force development and time to takeoff during the countermovement jump. Journal of Exercise Physiology Online, 10, 10-17.

Ebben, W. P., \& Petushek, E. J. (2010). Using the reactive strength index modified to evaluate plyometric performance. Journal of Strength and Conditioning Research, 24, 1983-1987.

Henderson, G., Barnes, C. A., \& Portas, M. D. (2010). Factors associated with increased propensity for hamstring injury in English Premier League soccer players. Journal of Science and Medicine in Sport, 13, 397-402.

Jidovtseff, B., Quievre, J., Harris, N. K., \& Cronin, J. B. (2014). Influence of jumping strategy on kinetic and kinematic variables. Journal of Sports Medicine and Physical Fitness, 54, 129-138.

Jiménez-Reyes, P., \& González-Badillo, J. J. (2011). Control de la carga de entrenamiento a través del CMJ en pruebas de velocidad y saltos para optimizar el rendimiento deportivo en atletismo [Monitoring training load through the CMJ in sprints and jump events for optimizing performance in athletics]. Cultura, Ciencia y Deporte, 6, 207-217.

Kirby, T. J., McBride, J. M., Haines, T. L., \& Dayne, A. M. (2011). Relative net vertical impulse determines jumping performance. Journal of Applied Biomechanics, 27, 207-214.

Kollias, I., Hatzitaki, V., Papaiakovou, G., \& Giatsis, G. (2001). Using principal components analysis to identify individual differences in vertical jump performance. Research Quarterly for Exercise and Sport, 72, 63-67.

Laffaye, G., Wagner, P. P., \& Tombleson, T. I. L. (2014). Countermovement jump height: Gender and sport-specific differences in the force-time variables. Journal of Strength and Conditioning Research, 28, 1096-1105.

Markovic, G., Dizdar, D., Jukic, I., \& Cardinale, M. (2004). Reliability and factorial validity of squat and countermovement jump tests. Journal of Strength and Conditioning Research, 18, 551-555. 
McGinnis, R. S., Cain, S. M., Davidson, S. P., Vitali, R. V., Perkins, N. C., \& McLean, S. G. (2016). Quantifying the effects of load carriage and fatigue under load on sacral kinematics during countermovement vertical jump with IMU-based method. Sports Engineering, 19, 21-34.

McMahon, J. J., Murphy, S., Rej, S. J. E., \& Comfort, P. (2017). Countermovement-jump-phase characteristics of senior and academy rugby league players. International Journal of Sports Physiology and Performance, 12, 803-811.

McMahon, J. J., Rej, S. J. E., \& Comfort, P. (2017). Sex differences in countermovement jump phase characteristics. Sports, $5,8$.

Moir, G. L. (2008). Three different methods of calculating vertical jump height from force platform data in men and women. Measurement in Physical Education and Exercise Science, 12, 207-218.

Olsson, N., Silbernagel, K. G., Eriksson, B. I., Sansone, M., Brorsson, A., Nilsson-Helander, K., \& Karlsson, J. (2013). Stable surgical repair with accelerated rehabilitation versus nonsurgical treatment for acute Achilles tendon ruptures: A randomized controlled study. American Journal of Sports Medicine, 41, 2867-2876.

Owen, N. J., Watkins, J., Kilduff, L. P., Bevan, H. R., \& Bennett, M. A. (2014). Development of a criterion method to determine peak mechanical power output in a countermovement jump. Journal of Strength and Conditioning Research, 28, 1552-1558.

Riggs, M. P., \& Sheppard, J. M. (2009). The relative importance of strength and power qualities to vertical jump height of elite beach volleyball players during the countermovement and squat jump. Journal of Human Sport and Exercise, 4, 221-236.

Runge, M., Rittweger, J., Russo, C. R., Schiessl, H., \& Felsenberg, D. (2004). Is muscle power output a key factor in the age-related decline in physical performance? A comparison of muscle cross section, chair-rising test and jumping power. Clinical Physiology and Functional Imaging, 24, 335-340.

Russo, C. R., Lauretani, F., Bandinelli, S., Bartali, B., Cavazzini, C., Guralnik, J. M., \& Ferrucci, L. (2003). High-frequency vibration training increases muscle power in postmenopausal women. Archives of Physical Medicine and Rehabilitation, 84, 1854-1857.

Salles, A. S., Baltzopoulos, V., \& Rittweger, J. (2011). Differential effects of countermovement magnitude and volitional effort on vertical jumping. European Journal of Applied Physiology, 111, 441-448.

Schmidtbleicher, D. (1992). Training for power events. In P. V. Komi (Ed.), Strength and power in sport (pp. 381-385). Oxford, United Kingdom: Blackwell.

Slinde, F., Suber, C., Surer, L., Edwén, C. E., \& Svantesson, U. (2008). Test-retest reliability of three different countermovement jumping tests. Journal of Strength and Conditioning Research, 22, 640-644.

Wisløff, U., Castagna, C., Helgerud, J., Jones, R., \& Hoff, J. (2004). Strong correlation of maximal squat strength with sprint performance and vertical jump height in elite soccer players. British Journal of Sports Medicine, 38, 285-288. 